International Journal of Applied Linguistics \& English Literature

ISSN 2200-3592 (Print), ISSN 2200-3452 (Online)

Vol. 1 No. 5; September 2012 [Special Issue on General Linguistics]

\title{
Insights From Verbal Protocols: A Case Study
}

\author{
Margaret Kumar (Corresponding author) \\ Student Learning and Development \\ Higher Education Development Centre \\ University of Otago \\ Dunedin 9054, New Zealand
}

Tel: $02102287850 \quad$ E-mail: margaret.rajoo@otago.ac.nz

Received: 26-06- 2012

doi:10.7575/ijalel.v.1n.5p.25
Accepted: 13-07- 2012

Published: 03-09- 2012

\begin{abstract}
This study explores a postgraduate student writer's responses and reactions through verbal protocols as she attends to teacher feedback. Teacher feedback has been heralded as an important element in process writing. Numerous studies have been carried out on various aspects of teacher feedback such as on the effectiveness of feedback, students' preferences for teacher feedback and students' perceptions of feedback. However, there is still a gap in the literature in determining how students respond as they engage with teacher feedback. This paper reports on one postgraduate student's responses on and her reactions to teacher feedback. Concurrent verbal protocols used in complement with written drafts and teacher commentaries were the main sources of data for this study. The analyses reveal that attending to feedback is a recursive process that fosters self-reflection which, in turn promotes planning for revision.
\end{abstract}

Keywords: Verbal protocols Teacher written feedback; Recursion; Reflection; Planning

\section{Introduction}

The importance of feedback in writing process has been widely researched and is considered to be an important component in English as a second language (ESL) writing environment especially for the development of second language writing skills (Hyland \& Hyland, 2006; Kroll, 2001). Bloxham and Boyd (2007) regard feedback as "the most important aspect of the assessment process in raising achievement" (p.20). Thus, in institutions of higher learning, providing written feedback is an essential element in the feedback process (Nicol, 2010). As second language (L2) writers find writing in an L2 a challenge (Zacharias, 2007), written feedback is essential and is a means by which writers can evaluate their own progression in writing towards achieving their goals. The crucial role of feedback is further reiterated by Murphy and Roopchand (2003) who claim that feedback engage students in challenging tasks. Besides helping writers to repair the errors, feedback also helps them to write (Flower \& Hayes, 1981). This enables them to understand their progress (Ryan, 1997) thus, facilitating the learning progress (Hyland, 1990).

\section{Related Literature}

Text Issues pertaining to students' writing occupy the centrality of L2 writing pedagogies and research underscore the importance of feedback for students in their learning process (Rowntree, 1977; Sadler, 1989). In the last decade, studies on feedback research have progressed rapidly (Ellis, Sheen, Murakami \& Takashima, 2008; Ferris, 2003; Hyland \& Hyland, 2006; Stern \& Solomon, 2006). Feedback studies have focused, for example, on types of feedback comments, direct or indirect feedback and students' preferences for feedback .

However, though some of these studies have looked at how feedback is perceived by students by looking at their cognitive processes (Cohen, 1987; Cohen \& Cavalcanti, 1990; Hyland, 1998, 2000, 2003), there is scarce research on the actual thought processes of student writers' engagement with teacher feedback and its use in their revision. Providing students timely and detailed written feedback comments on their strengths and weaknesses and suggestions on improving their writing will help students (Nicol, 2010). Students' writing improve significantly when they are provided feedback to respond to (Vardi, 2012). As students are seen as active agents in their own learning (Hyland \& Hyland, 2006), students' engagement with written feedback as they interact with and reflect and find solutions for their writing is important. The present study examines a writer's thought

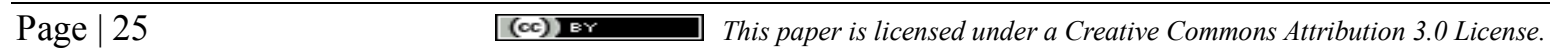


International Journal of Applied Linguistics \& English Literature

ISSN 2200-3592 (Print), ISSN 2200-3452 (Online)

Vol. 1 No. 5; September 2012 [Special Issue on General Linguistics]

processes obtained through concurrent verbal protocols as she engages with teacher written feedback that aids her to "monitor, evaluate and regulate" (Nicol, 2010, p.504) her own learning.

Previous studies generally focused on feedback in relation to the holistic improvement of students' writing quality. This study however, is unique because it investigates the whole process of generating and receiving feedback, from its inception to its implementation in revisions in students' L2 by recording their thought processes. It utilizes the think-aloud protocols, written teacher feedback comments and written drafts to ascertain how a writer respond to teacher feedback and investigate a writer's thought processes as she attends to teacher feedback.

2.1 Models of writing

Since the 1970's writing research has shifted from focusing on written products to thinking process of the writer which has led to the development of models of composing process. The theoretical underpinning of the cognitive process models is that writing is recursive. Cognitive process theories aim to provide an understanding of how writing is learned and developed. They examine the relationship between how writers think and the activities in which they engage throughout the process of writing.

This shift in writing paradigm saw the emergence of theoretical models of writing such as those of Hayes and Flower (1980), Bereiter and Scardamalia (1987) and Hayes (1996) that give insights into writers' cognitive processes of revision in the process of writing. These models of writing suggest the recursive nature of writing process (Hayes, 1996) that pushes writers through various stages of writing to realize their intended goals. However, these models do not give clear insights about the role of teacher's written feedback as input in the recursion process of writing that leads to reflection and planning. In studies examining the thought processes of writers as they engaged with feedback (Kumar \& Kumar, 2009; Kumar, Kumar \& Feryok, 2009), it was established that attending to feedback is a recursive process where the writer moved forth and back in no set order between feedback and their written texts before making decisions and finding solutions for the problems highlighted in teacher feedback. Though these studies gave a glimpse into the recursiveness that took place while engaging with teacher's written comments, insights into the relationship between other cognitive processes such as reflection and planning that evolved as writers engaged in the process of attending to teacher's written feedback were not reported. In addition, literature on writers' engaging with feedback recursively is scarce.

\subsection{Reflection}

Reflection is a cognitive activity in problem-solving where students deliberate, infer, make choices, and make decisions about alternatives and executing them (Hayes, 1996; Van Manen, 1991). Writers need to pause and reflect on feedback to enable them to move forward. Reflection is a necessary component in improving writing as it provides writers the opportunities to link what they had written and understand what is needed to meet the demands outlined by teacher's comments. Writers thus become aware of what they initially produced and the course of action they need to take (van den Boom, Paas \& van Merrienboer, 2007) by reflecting to progress in their writing.

Thus, when reflecting on teacher comments, writers weigh, make connections between feedback and their writing, and evaluate feedback given on their drafts before coming to a decision regarding their writing. Feedback provides the channel for reflection (Valli, 1990) and prompts writers to reflect on strategies that they could adopt and interpret to meet the requirements of teacher comments (Laurillard, 1993). By reflecting, "the processes of learning are made visible to the students and they themselves take responsibility for their own improvement (Granville \& Dison, 2009, p.60). Though there is a substantial amount of literature on reflection in various fields, literature in relation to teacher written feedback, however, is scarce. This study, thus aims to provide a glimpse of the cognitive process of reflection that developed as a writer engaged with written teacher feedback.

\subsection{Planning}

The process approach is a recursive procedure which encompasses a series of discreet stages of writing, which writers employ through a variety of cognitive processes, such as planning, retrieving ideas from memory, making inferences, creating and developing concepts (Hayes \& Flower, 1980). Planning refers to the mental activity that writers engage in making decisions and judgments to achieve their writing goals (Stosky, 1990). The process approach to teaching writing allows for intervention at any stage of the writing process. The process of planning, then, allows for the unfolding of writing by way of preparing action plans for writing (Hayes \& Gradwohl-Nash, 1996). Teacher feedback taking on the role of intervention plays an important role as it has the potential to further develop writers' skills and orchestrate the text generated to meet the demands of teacher feedback. 
International Journal of Applied Linguistics \& English Literature

ISSN 2200-3592 (Print), ISSN 2200-3452 (Online)

Vol. 1 No. 5; September 2012 [Special Issue on General Linguistics]

Cognitive models of writing such as those mentioned above emphasize the role of planning in the writing process. These models suggest that planning is an activity that not only takes place at the onset of writing, but is a recursive process that occurs at any stage of the writing process. Though studies on planning have established that writers plan to generate ideas before translating them into words on paper, there is, however little literature on writers' thought processes on planning as they attend to teacher written feedback. Since planning begins with reading feedback (van den Boom, Paas, \& van Merrienboer, 2007), this study aims to highlight a writer's thought process on planning, a component of the writing process which occurred as a result of teacher feedback. 2.4 The Think-Aloud Method

In order to gain insights into the thought processes, a method known as the think-aloud method was used in this study. Concurrent verbal protocols, a branch of the think-aloud method, have been advocated as a technique of collecting information by tapping directly into learners' thoughts (Wigglesworth, 2005), giving direct access to the mental processes of writers (Scardamalia \& Bereiter, 1986). Since data is collected while a task is being performed, participants verbalize spontaneously without altering their cognitive processes which closely matches the flow of their cognitive processes (Green, 1995). As concurrent verbal reports are seen as trustworthy evidence of events perceived or noticed (Schmidt, 2001), data obtained would be an actual reflection of writers' mental process. Though it has been argued that not all writers' thoughts will be verbalized and that verbalizing may lead to increased attention and deeper processing (Jourdenais, 2001), verbal protocols have been regularly used by researchers to get insights of writers' thought processes simply because there is no other way of doing so (Ericsson \& Simon, 1993). Studies have revealed that participants using the concurrent method reflect information processes from the short term memory (Kussela \& Paul, 2000), thus reflecting what they are actively engaged in doing at the time of the think-aloud.

Researchers (Bowles, 2008; Bowles \& Leow, 2005; Cohen \& Cavalcanti, 1990; Hayes \& Flower, 1980; Sachs \& Polio, 2007) in the past have used verbal protocols to give insights into the writing processes of planning, translating, and reviewing. However though this technique allowed researchers to capture writers' thought processes as they composed (Hayes \& Flower, 1980), the recursive processes that writers engage in or the thought processes of writers as they attended to teacher feedback and their responses to feedback such as self-reflection and planning is virtually non-existent. To gain insights on the sequence of thoughts of writers, examining the thought processes of writers as they deal with feedback given on their writing could provide insights into how and possibly even why student writers approach feedback. The present study examines the actual thought processes of a student writer as she attends to written teacher feedback and revises by means of concurrent verbal protocols to obtain "observable, externalized data from unobservable, internalized processes to draw conclusions from the processes" (Wigglesorth, 2005, p. 101).

However, a serious criticism leveled at concurrent verbal protocol is the issue of reactivity. Reactivity refers to the disruption that may occur in writers' cognitive process (Janssen, van Waes \& van den Bergh, 1996; Jourdenais, 2001; Russo, Johnson, \& Stephens, 1989, Smargorinsky, 2001) when they are faced with the dual task of writing and verbalizing their thoughts at the same time. Previous studies on cognition (Bowles, 2008; Bowles \& Leow, 2005; Leow \& Morgan, 2004; Sachs \& Polio, 2007; Sanz, Lin, Lado, Bowden \& Stafford, 2009) suggest that reactivity can be viewed as potentially problematic as it might alter the process and thus compromise direct access to writers' cognitive process. However, despite the criticism, there is little evidence to prove that writers' internal processes are altered in any way (Ericsson \& Simon, 1993; Smagorinsky, 1989).

Feedback in the past has generally focused on teachers, particularly the strategies they use in giving feedback, their perceptions of students' needs and the impact of their feedback on students' writing (Ferris, 2007; Hyland \& Hyland, 2001; Stern \& Solomon, 2006). They generally focused on feedback in relation to the holistic improvement of students' writing quality by providing a glimpse of the cognitive processes used when writers attend to the various stages of writing such as consideration of an audience, contextual factors, the recursive nature of planning, generation of ideas and revision. There is a paucity of literature on what ESL students so when they engage with teacher feedback and how they respond to teacher feedback. This study however, is unique because it investigates the whole process of generating and receiving feedback, from its inception to its implementation in revisions in students' L2 by recording their thought processes. It utilizes the think-aloud protocols, written teacher feedback comments and written drafts to ascertain how a writer respond to teacher feedback and investigate a writer's thought processes as she attends to teacher feedback.

2.5 Research questions

There has been little research on L2 students' thought processes as they attend to feedback: their reactions to teacher feedback, their understanding of and response to teacher feedback and their use of teacher feedback in subsequent revision. This study thus, attempts to investigate this area of inquiry into teacher feedback. It is 
International Journal of Applied Linguistics \& English Literature

ISSN 2200-3592 (Print), ISSN 2200-3452 (Online)

Vol. 1 No. 5; September 2012 [Special Issue on General Linguistics]

concerned with how teacher feedback fits into the process of developing writing skills by examining how ESL writers respond to teacher written feedback and utilize it in their writing and seeks to answer the following research questions:

1. What thought processes does a student writer go through while attending to written teacher feedback?

2. How does a student writer respond to teacher feedback?

\section{The study}

\subsection{Setting}

The case study reported here is part of a larger study involving eight ESL postgraduate students enrolled in a Master of Arts program doing a course in Research and Practice in Composition at a Malaysian public university. Ethical procedures were followed and the participants' consent was obtained prior to research. Data obtained from the participants was in the form of concurrent verbal protocols, written essays and teacher written comments.

\subsection{Participant}

The participant in this study was Sham (pseudonym), a 24 year old who uses English as a second language. She is currently in her second year in the Master of Arts program majoring in English for Specific Purposes and is fluent in English. She was selected for the study from a pool of twenty-seven other volunteers because of her proficiency in the English language where she attained a Band Five in the Malaysian University English and the rich verbalizations that she was able to provide during the training sessions.

\subsection{Training sessions}

Prior to the study, the researcher held two think-aloud training sessions to enable the participants to familiarize themselves of thinking aloud while attending to another task simultaneously. This provided the opportunity for the participants to be comfortable with the idea of thinking aloud which is a departure from their usual way of attending to teacher feedback and at the same time gave the participants a chance to practice thinking aloud while completing sample tasks. The training sessions were also expected to dispel any concerns that the participants may have of attending to the dual task of verbalizing and executing a task concurrently. The participants were selected based on the rich verbalizations they were able to produce while attending to written feedback.

\subsection{Data collection}

A lecturer teaching the writing class assisted in the collection of the data. The participants who were selected for the actual study were required to write an argumentative academic writing as part of the course requirement on the following writing prompt which is taken from Raimes (1987): Success in education is influenced more by the student's life and training as a child than by the quality and effectiveness of the educational programme. The participants were given the opportunity to write at their own convenience and no time limit was placed on their writing. On completion of their initial drafts, their writings were handed in to the lecturer who then gave written feedback on their drafts. The drafts with the lecturer feedback were sealed in an envelope and given to the writers. They were required to record their verbalizations about their feelings, reactions, what they planned to do and whatever thoughts that came to their minds aloud as they attended to the written feedback on their writing. Their recorded verbalizations, original drafts and revised drafts were handed to their lecturer and collected by the researcher for analysis.

\subsection{Data analysis}

Written texts were used in combination with the verbal protocols and teacher written comments to ascertain if revision was evident in the participant's revised text. Verbal data was coded and analyzed through constant comparison (Glasser \& Strauss, 1967) until its completion (Cohen, Manion, \& Morrison, 2007; Merriam, 2001). A set of codes (Appendix A) based on the writers' thought processes were developed by the researcher and the independent coder. Data was then coded iteratively with the independent coder. No significant differences occurred during the coding procedures.

\section{Results and discussion}

In this section, Sham's responses and reactions as she attended to the feedback comments on her initial draft are discussed. Sham attended to teacher feedback recursively. As evidenced by Sham's verbal protocols, this process of recursively attending to teacher feedback led her to reflect on the feedback comments on her text. Her 
International Journal of Applied Linguistics \& English Literature

ISSN 2200-3592 (Print), ISSN 2200-3452 (Online)

Vol. 1 No. 5; September 2012 [Special Issue on General Linguistics]

reflection on teacher feedback in turn extended her the opportunity to plan for her revisions globally based on the feedback given to her.

Sham had a total of twenty-six points of feedback ranging from content, organization and language. Sham attended to all of the twenty six feedback commentaries that were given on her draft. It was evident in her revised draft that Sham took all the feedback comments that were given to her into consideration and incorporated these in her revision.

\subsection{Thought processes}

Sham's verbal protocols indicate that she accepted all the feedback comments that she attended to without any reservations. The following extract is an extended example of Sham engaging with one point of feedback which shows the various and strategies she made use of in addressing teacher feedback. For instance, when Sham attended to the following teacher feedback (TFB): These are indeed valid points. However, I wonder if you could revise this paper to be an argumentative academic paper. You have to structure your argument, take a stand and then tell me what your points are to support your claims take a stand and tell me what your points are (L1) Sham employs various strategies such as reading feedback, rereading feedback, and referring to feedback; and engages in various responses such as giving reasons, indicating her understanding, and accepting feedback. And finally, when she accepts the feedback, she reflects on the feedback and comes up with an action plan to address the feedback comments that were incorporated in her revised draft.

Sham's attendance to teacher feedback gave rise to three insights. Firstly, she recursively attended to teacher feedback. Secondly, attending to feedback gave Sham the opportunity to reflect and thirdly, engaging with teacher feedback led to planning.

\subsection{Recursion}

The first insight of this study is that the writer was recursive throughout her attendance to feedback. Sham in this study moved back and forth repeatedly and cyclically between feedback comments and her written text in no set order. The extracts (Appendix B) show that Sham moved repeatedly between one point of feedback comment and her essay trying to understand the objective of the feedback. In the course of attending to feedback Sham showed her understanding of the feedback and her acceptance of it to be included in her revision which finally led her to self-reflect and plan for her revision (see sections on self-reflection and planning). Perhaps these acts of recursiveness are closely related to the manner and content of the teacher feedback itself (Hyland \& Hyland, 2001; Baker \& Bricker, 2010). The complexity of teacher feedback instead of a directive possibly provided the need for Sham to revisit the feedback several times before making a choice.

These recursive movements seem to be consistent with the theoretical models of writing mentioned earlier that emphasize and give insights into a writer's cognitive processes of revision in the process of writing. These models of writing suggest the recursive nature of the writing process (Hayes, 1996) that pushes writers through the various stages of writing to realize their intended goals. However, these models do not give clear insights about the role of teacher feedback as input in the recursion process of writing. These recursive movements that Sham engaged gave her the opportunity to understand and accept teacher feedback and move on with her next course of actions. Recursion, thus, pushed Sham through the various cognitive processes to achieve her writing goals that are evident in her revised draft.

Just like writing which is a recursive process, attending to feedback is also a recursive process, a process in which writers constantly evaluate their ideas and their drafts with respect to teacher feedback. By recursively engaging with feedback, Sham showed her understanding of the purpose of the feedback she received (Bailey \& Vardi, 1999) and accepted teacher feedback. Many studies have highlighted the importance of the recursive feature that occurs with planning, composing, translating and reviewing (Faigley \& Witte, 1981; Hayes \& Flower, 1980). During the recursive stages, Sham revised her existing text and re-envisioned her thoughts and ideas in the process of attending to teacher feedback. Recursively attending to feedback encouraged Sham to reflect and plan her writing which is discussed in the following sections.

\subsection{Reflection}

A second insight of this study is that engagement with feedback and thinking aloud led Sham to reflect on teacher feedback. The following extract is one extended instance of Sham adopting various strategies in trying to make sense of teacher feedback. She reads aloud (RFB) part of one point of teacher feedback first: These are indeed valid points. However I wonder if you could revise this paper to be an argumentative academic paper (L2), Sham responses positively by accepting feedback (ATFB) in this manner: Yap surely I will. I will try my best 
International Journal of Applied Linguistics \& English Literature

ISSN 2200-3592 (Print), ISSN 2200-3452 (Online)

Vol. 1 No. 5; September 2012 [Special Issue on General Linguistics]

(L3). She then continues to read the next part of the feedback (RFB): This means that you have to structure your argument, take a stand and then tell me what your points are to support your claims (L4) and accepts it (ATFB) when she says, ok, I can do that (L5). She then rereads part of the same feedback (RRFB): structure your argument (LG) perhaps to get a better understanding (U) of it, evident as she voices aloud her insight into the comment in this manner: structure, first, second, third, ok I get it (L7). Sham then rereads (RRFB); structure your argument (L8). Her review of teacher feedback comment prompted her to reflect (REF) on the approach she needs to take to address feedback comment in this way: ok, how am I going to structure my arguments (L9). Sham's reflection on teacher comment in turn led to her understanding $(\mathrm{U})$ and acceptance of teacher feedback (ATFB) which is apparent in the following think-aloud: ok, I will have to provide an argument (L10) and, this in turn prompted her to generate plans (PL) for her rewrite which is discussed in the section on planning.

By reflecting on feedback, Sham was able to identify the differences that appeared between her text and teacher comments and was able to make the connection and find solution for the problem. This process of looking back and forward within phases of feedback and reflection enabled Sham to become strategic and plan on her next course of action to meet the requirements of teacher feedback. Reflection enabled Sham to understand teacher comments and was able to integrate her plans in her revised draft.

Reflecting on teacher feedback made Sham become aware of her writing problems and enabled her to proceed with her revision. This was clearly seen as Sham reflected and responded to teacher feedback which is reflected in the changes that are apparent in her revision. Thus, attending to teacher feedback and thinking-aloud, as a form of output, appears to have generated the reflective function that Swain (1995) has identified.

In the context of this study, teacher feedback is not just a pedagogical tool that a teacher uses to teach writing but requires students to be actively engaged with feedback to make the connections between the feedback and their objectives of writing (Granville \& Dison, 2009). In this instance, teacher feedback acted as an intervention platform which gave her the space and opportunity for her to reflect on teacher feedback and at the same time generate new ideas and approaches that she could adopt in her revision.

This study aimed to provide a window on the cognitive process of reflection that emerged as a writer engaged with teacher feedback that encouraged and enhanced the writer to think and plan for revision. A vital element that emerged in the process of reflection is planning that was an ongoing process in the process of attending to feedback and writing.

\subsection{Planning}

A third insight of this study is that the writer planned as a result of attending to teacher feedback on her initial drafts. Sham's think-aloud protocols show evidence that she planned as she recursively moved back and forth from teacher feedback and her written texts to achieve her goals as suggested by teacher feedback. She accepts and planned (PL) her strategies for revision based on teacher feedback mentioned above to meet the suggestions made on her writing is illustrated in the following extract: so basically the argument for this piece of writing is the question itself and my four points. That means I talk about factors influencing a child in his growing up process. That can be my stand (L11). Sham revisits the feedback (RRFB) in the following lines: Take a stand and tell me what your points are to support your stand (L12) and comes up with further plans (PL) for revision evident in the following extract: one stand and supporting points so I choose only one. Both life and training as a child or quality and effectiveness of the education programme. I am not going to deal with two ideas but one and my points to support the argument. I am going to choose student's life and training as a child in which I can actually talk more about what I feel and also support it with the proper evidence (L13).

Planning resulting from engagement with teacher feedback did improve Sham's revised essay. A marked difference occurred as a result of engaging recursively with teacher feedback, reflecting and planning. In her first draft Sham did not express her stand explicitly nor did she say what she was going to talk about. The following is an extract of her original draft where she began her essay by relating her own experiences, writing in this manner: I went through a tough time to be what I am right now. ...the success that we gain through education will not only benefit us in our career but is actually the main tool which will shape our entire life. However, in Sham's revised essay, there are indications that she took teacher feedback on board and actually implemented what she planned, as evident in the following extract of her revised essay. In this paper I will provide an argument that success in education is influenced more by the student's life and training as a child than by the quality and effectiveness of the educational programme. The four main points to support this stand are: student's life and training ... parents' roles in a child's education ... the importance of culture and society ... and student's self-awareness in acquiring knowledge. The extract illustrates the outcome of Sham's engagement with

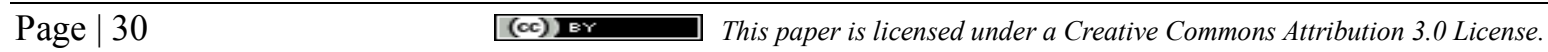


International Journal of Applied Linguistics \& English Literature

ISSN 2200-3592 (Print), ISSN 2200-3452 (Online)

Vol. 1 No. 5; September 2012 [Special Issue on General Linguistics]

teacher feedback where she makes a general statement and then indicates that there are four points to support it, just as the teacher feedback suggested she do.

There are two major benefits of planning in writing (Hayes \& Gradwohl-Nash, 1996). First, planning provides goals and means to complete the writing task. Secondly, planning provides writers with choices in problem solving strategies as it gives them access to various resources in the planning environment like it did for Sham. Studies comparing experienced and novice writers have shown that more planning leads to more and better writing. The amount of time writers spend planning and the kinds of decisions they make during planning attests to the quality of writing (Perl, 1981). Perhaps as Sham is an experienced writer, and had no time constraints on the task given to her, she took her time to plan her revisions as she attended to teacher feedback, a fact that is reflected in her revision.

\section{Conclusion}

The role of teacher written feedback is of paramount importance if one aims to help writers develop their potential as writers. It is feedback that provides a sense of direction and tells the writers of the writing goals that are achievable. This study affirms the importance of providing written feedback that encourages recursion leading to revisions. As feedback is essential for the development of second language writing skills (Hyland \& Hyland, 2006), teacher feedback in this case study played a positive intervention role in assisting Sham to bridge the disparities that were present in her writing. It helped her to understand and 'view' how well she wrote and how she might further develop her writing (Ryan, 1997) when she revised her first draft. Recursive movements between teacher feedback and texts helped Sham to identify and evaluate the issues highlighted in teacher feedback which ultimately culminated in the writer making major changes to her revised drafts. By moving recursively between her text and her feedback, she had the opportunity to evaluate her initial drafts in light of teacher feedback, and revisit her written text in an effort to further enhance her writing, striking a balance between what she intend to say as a writer and what is understood by readers, as indicated by teacher feedback.

In line with Hyland and Hyland's (2006) observation that students should be actively engaged in the feedback process, Sham took an active role to make sense of teacher feedback. She pursued teacher feedback with further thinking and rethinking, reading and rereading which not only led to her noticing the disparities between teacher feedback and her texts but also to addressing these disparities by reflecting on teacher feedback and making plans which eventually led her to substantively revise her initial drafts by incorporating teacher feedback comments.

Though this study is an exploratory case study of the thought processes of one writer, it however offers some insights into the thought processes of a writer as she attended to teacher feedback while thinking-aloud concurrently and suggests two pedagogical implications. First, recursiveness could be taught or modeled by teacher to student writers as a method of engagement with teacher feedback to promote thinking to further develop their writing skills. This could be way of making students become aware of what is expected of them when they are given feedback.

Second, the role of think-aloud as a technique to enhance thinking about feedback that is given on students' writing. The very act of thinking about feedback itself could promote development among writers (Swain, 2006). However, further studies covering a range of factors such involving participants across different levels and courses, nationalities and disciplines would need to be carried out.

\section{References}

Bailey, J., \& Vardi, I. (1999). Iterative feedback: Impacts on student writing. Paper presented at the HERDSA Annual International Conference, 12-15 July, Melbourne.

Baker, W., \& Hansen Bricker, R. (2010). The effects of direct and indirect speech acts on native English and ESL speakers' perception of teacher written feedback. System, 38(1), 75-84. doi: 10.1016/j.system.2009.12.007 Bereiter, C., \& Scardamalia, M. (1987). The psychology of written composition. Hillsdale, NJ: Lawrence Erlbaum Associates.

Bloxham, S., \& Boyd, P. (2007). Developing effective assessment in higher education: A practical guide. Cambridge: Open University Press.

Bowles, M. (2008). Task type and reactivity of verbal reports in SLA: A first look at an L2 task other than reading. Studies in Second Language Acquisition, 30(4), 359-379. 
International Journal of Applied Linguistics \& English Literature

ISSN 2200-3592 (Print), ISSN 2200-3452 (Online)

Vol. 1 No. 5; September 2012 [Special Issue on General Linguistics]

Bowles, M. A., \& Leow, R. P. (2005). Reactivity and type of verbal report in SLA research methodology:

Expanding the scope of investigation. Studies in Second Language Acquisition, 27(3), 415-440.

Cohen, A. D. (1987). Student processing of feedback on their compositions. In A. L. Wenden \& J. Rubin (Eds.),

Learner strategies in language learning (pp. 57-69). Englewood Cliffs, NJ: Prentice-Hall.

Cohen, A. D., \& Cavalcanti, M. (1990). Feedback on compositions: Teacher and student verbal reports. In B.

Kroll (Ed.), Second language writing: Research insights for the classroom (pp. 155-177). New York: Cambridge University Press.

Ellis, R., Sheen, Y., Murakami, M., \& Takashima, H. (2008). The effects of focused and unfocused written corrective feedback in an English as a foreign language context. System, 36(3), 353-371.

Ericsson, K. A., \& Simon, H. A. (1993). Protocol analysis: Verbal reports as data. Cambridge: MIT Press.

Faigley, L., \& Witte, S. P. (1981). Analysing revision. College Composition and Communication, 32, 400-414.

Ferris, D. (2003). Response to student writing. Mahwah, NJ: Lawrence Erlbaum Associates.

Ferris, D. (2007). Preparing teachers to respond to student writing. Journal of Second Language Writing, 16(3), 165-193.

Flower, L., \& Hayes, J. R. (1981). A cognitive process theory of writing. College Composition and Communication, 32(4), 365-387.

Granville, S., \& Dison, L. (2009). Making connections through reflection: Writing and feedback in an academic literacy programme. Southern African Linguistics and Applied Language Studies, 27, 53-63.

Green, A. (1995). Verbal protocol analysis. The Psychologist, 8(3), 126-129.

Hayes, J. R. (1996). A new framework for understanding cognition and affect in writing. In C. M. Levy \& S.

Ransdell (Eds.), The science of writing: Theories, methods, individual differences and applications. (pp. 1-27).

Mahwah, NJ: Lawrence Erlbaum Associates.

Hayes, J. R., \& Flower, L. (1980). Identifying the organization of writing processes. In L. W. Gregg \& E. R.

Steinberg (Eds.), Cognitive processes in writing: An interdisciplinary approach (pp. 3-30). Hillsdale, NJ:

Lawrence Erlbaum Associates.

Hayes, J. R., \& Gradwohl-Nash, J. (1996). Onthe nature of planning in writing. In C. M. Levy \& S. E. Ransdell

(Eds.), The science of writing: Theories, methods, individual differences, and applications (pp. 29-55). Mahwah, NJ: Lawrence Erlbaum.

Hyland, F. (1998). The impact of teacher written feedback on individual writers. Journal of Second Language Writing, 7(3), 255-286.

Hyland, F. (2000). ESL Writers and feedback: Giving more autonomy to students. Language Teaching Research, 4(1), 33-54.

Hyland, F. (2003). Focusing on form: Student engagement with teacher feedback. System, 31(2), 217-230.

Hyland, F., \& Hyland, K. (2001). Sugaring the pill: Praise and criticism in written feedback. Journal of Second Language Writing, 10(3), 185-212.

Hyland, K. (1990). Providing productive feedback. ELT Journal, 44(4), 279-285.

Hyland, K., \& Hyland, F. (2006). Feedback in second language writing: Contexts and issues. Cambridge:

Cambridge University Press.

Janssen, D., van Waes, L., \& van den Bergh, H. (1996). Effects of thinking aloud on writing processes. In C. M. Levy \& S. Ransdell (Eds.), The science of writing (pp. 223-250). Mahwah, NJ: Lawrence Erlbaum Associates.

Jourdenais, R. (2001). Cognition, instruction and protocol analysis. In P. Robinson (Ed.), Cognition and second language instruction (pp. 354-375). New York: Cambridge University Press.

Kroll, B. (2001). Considerations for teaching in an ESL/EFL writing course. In M. Celce-Murcia (Ed.), Teaching English as a second or foreign language (pp. 219-232). Boston, MA: Heinle and Heinle.

Kumar, M., Kumar, V., \& Feryok, A. (2009). Recursiveness in written feedback. New Zealand Studies in Applied Linguistics, 15(1), 26-37.

Kumar, V., \& M, K. (2009). Recursion and noticing in written feedback. European Journal of Social Sciences, 12(1), 94-99.

Kussela, H., \& Paul, P. (2000). A comparison of concurrent and retrospective verbal protocol analysis. American Journal of Psychology, 113(1), 387-404.

Laurillard, D. (1993). Rethinking university teaching: A framework for effective use of educational technology. London: Routledge.

Leow, R. P., \& Morgan-Short, K. (2004). To think aloud or not to think aloud: The issue of reactivity in SLA research methodology. Studies in Second Language Acquisition, 26, 35-57. 
International Journal of Applied Linguistics \& English Literature

ISSN 2200-3592 (Print), ISSN 2200-3452 (Online)

Vol. 1 No. 5; September 2012 [Special Issue on General Linguistics]

Murphy, H., \& Roopchand, N. (2003). Intrinsic motivation and self-esteem in traditional and mature students at a post-1992 university in the north-east of England. Educational Studies, 4(1), 243-259.

Nicol, D. (2010). From monologue to dialogue: Improving written feedback processes in mass higher education. Assessment \& Evaluation in Higher Education, 35(5), 501-517.

Perl, S. (1981). Coding the composing process: A guide for teachers and researchers. National Institute of Education, Washington, D. C.

Rowntree, D. (1977). Assessing students: How shall we know them? London: Harper and Row.

Ryan, K. (1997). Teacher comments and student responses. Directions in Teaching and Learning, 69, 5-13.

Sachs, R., \& Polio, C. (2007). Learners' use of two types of written feedback on an L2 writing revision task.

Studies in Second Language Acquisition, 29(1), 67-100.

Sadler, D. R. (1989). Formative assessment and design of instructional systems. Instructional Science, 18, 119-144.

Sanz, C., Lin, H.-J., Lado, B., Bowden, H., \& Stafford, C. A. (2009). Concurrent verbalizations, pedagogical conditions, and reactivity: Two CALL studies. Language Learning, 59(1), 33-71.

Scardamalia, M., \& Bereiter, C. (1986). Research on written composition. In M. Wittrock (Ed.), Handbook of research on teaching (3rd ed., pp. 778-803). New York: McMillan.

Schmidt, R. (2001). Attention. In P. Robinson (Ed.), Cognition and second language instruction (pp. 3-32).

Cambridge, England: Cambridge University Press.

Smagorinsky, P. (1989). The reliability and validity of protocol analysis. Written Communication, 6, 463-479.

Smagorinsky, P. (2001). Rethinking protocol analysis from a cultural perspective. Annual Review of Applied

Linguistics, 21, 233-245.

Stern, L. A., \& Solomon, A. (2006). Effective faculty feedback: The road less traveled. Assessing Writing, 11, $22-41$.

Stotsky, S. (1990). On planning and writing plans. Or beware of borrowed theories! College Composition and Communication, 41(1), 37-57.

Swain, M. (1995). Three functions of output in second language learning. In G. Cook \& B. Seidlhofer (Eds.),

Principle and practice in applied linguistics: Studies in honour of H. G. Widdowson (pp. 125-144). Oxford:

Oxford University Press.

Swain, M. (2006). Verbal protocols: What does it mean for research to use speaking as a data collection tool? In M. Chaloub-Deville, C. A. Chapple \& P. Duff (Eds.), Inference and generalizability in applied linguistics (pp. 97-113). Amsterdam: John Benjamins.

Valli, L. (1990). Reflective and teacher education: Cases and critiques. Albany: State University of New York Press.

Vardi, I. (2012). The impact of iterative writing and feedback on the characteristics of tertiary students' written texts. Teaching in Higher Education, 17(2), 167-179.

Wigglesworth, G. (2005). Current approaches to researching second language learner processes. Annual Review of Applied Linguistics, 25, 98-111.

Zacharias, N. T. (2007). Teacher and Student Attitudes toward Teacher Feedback. RELC Journal, 38(1), 38-52. doi: $10.1177 / 0033688206076157$

\section{Appendix A}

A sample of the think-aloud codes

\begin{tabular}{|l|l|l|}
\hline CODES & MEANINGS & EXAMPLES \\
\hline TFB & Teacher feedback & You have written clearly and concisely \\
\hline RFB & Reads feedback (exact words & $\begin{array}{l}\text { State your stand in the first paragraph. } \\
\text { Provide a link to your paragraphs. }\end{array}$ \\
\hline RRFB & $\begin{array}{l}\text { Rereads or reviews parts/whole } \\
\text { of feedback }\end{array}$ & $\begin{array}{l}\text { Stand in paragraph? Links to paragraph. } \\
\text { (repetition of part of the think-aloud coded as RFB } \\
\text { above) }\end{array}$ \\
\hline U & Understands feedback positively & ok, I get it \\
\hline ATFB & $\begin{array}{l}\text { Accepts/acknowledges teacher } \\
\text { feedback }\end{array}$ & I agree with that/ I can do that \\
\hline REF & Reflects/seeks solutions & How am I going to provide evidence? \\
\hline PL & Plans for revision & This is how I am going to structure my ... \\
\hline
\end{tabular}

Page $\mid 33$ 
International Journal of Applied Linguistics \& English Literature

ISSN 2200-3592 (Print), ISSN 2200-3452 (Online)

Vol. 1 No. 5; September 2012 [Special Issue on General Linguistics]

\section{Appendix B}

\section{Extracts of think-aloud protocols on one point of feedback}

L1 These are indeed valid points. However, I wonder if you could revisit this paper to be an argumentative academic paper. You have to structure your argument, a stand and then tell me what your points are to support your claims take a stand and tell me what your points are (TFB)

L2 These are indeed valid points. However, I wonder if you could revise this paper to be an argumentative academic paper $(R F B)$

L3 yap surely I will. I will try my best (ATFB)

L4 This means that you have to structure your argument, take a stand and then tell me what your points are to support your claims (RFB)

L5 ok, I can do that (ATFB)

L6 structure your argument (RRFB)

L7 structure, first, second, third, ok I get it (U)

L8 structure your argument (RRFB)

L9 ok, how am I going to structure my argument (REF))

L10 ok, I will have to provide and argument (U, ATFB)

L11 so basically the argument for this piece of writing is the question itself and my four points, ok, that means I talk about factors influencing a child in his growing up process. That can be my stand (PL)

L12 Take a stand and then tell me what your points are to support your stand (RRFB)

L13 one stand and supporting points so I choose only one. Both life and training as a child or quality and effectiveness of the education programme. I am not going to deal with two ideas but one and my points to support the argument. I am going choose student's life and training as a child in which I can actually talk more about what I feel and also support it with the proper evidence (PL) 